\title{
Commentary
}

\section{The Role of Carbonic Anhydrases in Tumors}

\author{
Antal Nógrádi \\ From the Department of Ophthalmology, Albert Szent-Gyorgyi \\ Medical University, Szeged, Hungary
}

Ever since Meldrum and Roughton discovered carbonic anhydrase $^{1}$ (CA; EC 4.2.1.1.), the zinc-containing metalloenzyme that catalyzes the reversible hydration of $\mathrm{CO}_{2}$ $\left(\mathrm{CO}_{2}+\mathrm{H}_{2} \mathrm{O} \leftrightarrows \mathrm{HCO}^{-}{ }_{3}+\mathrm{H}^{+}\right)$, the role of the enzyme has been thoroughly investigated. It has become clear that the main functions of the enzyme are to produce $\mathrm{HCO}_{3}^{-}$ for the intermediate metabolism and to maintain $\mathrm{pH}$, water, and ion equilibrium in the body. ${ }^{2}$ The presence of the enzyme has been proven essential in almost every organ. A series of studies performed over many years described nine isozymes (CA I through IX) ${ }^{3,4}$ and several CArelated peptides/proteins. ${ }^{5,6}$ CAs show various levels of catalytic activity and binding to inhibitors, they have considerable diversity in tissue distribution and cellular and subcellular localization, and they perform a variety of biological functions. ${ }^{2-4,7} \mathrm{CA} /$ is most abundant in erythrocytes, but its activity is only $15 \%$ that of CA II. CA II is a high-activity isozyme with the widest cytosolic distribution of the CAs. CA III is a very low-activity cytosolic isozyme mainly localized in slow-twitch red skeletal muscle fibers. CA IV is the membrane-bound isoform present in the nervous system, lung, kidney, heart, and some microcapillaries of the body. It has a high activity similar to that of CA II. CA V is a nuclear-encoded, mitochondrial isozyme. Its function appears important in gluconeogenesis and ureagenesis, as these pathways depend on some mitochondrial enzymes. CA VI is a secretory glycoprotein present in saliva. CA VII is a mysterious isozyme, because its sequence was analyzed before the protein was purified, but no proper function has been associated with the protein so far.

There are several CA-related peptides/proteins that show sequence homology to CAs without CA catalytic activity. One of the most interesting CA-related molecules is the CA-related polypeptide ${ }^{6}$ (CARP, previously referred to as CA VIII), which seems to be expressed in Purkinje cells during development, ${ }^{8}$ although other localizations of this protein cannot be excluded. The human homologue is $98 \%$ identical with mouse CARP, reflecting a high degree of conservation. Several forms of receptortype tyrosine phosphatases (RPTPs) show remarkable homology with CA sequences but have no CA activity. These are transmembrane proteins with proposed func- tions such as tumor suppressor protein ${ }^{9}$ (RPTP $\gamma$ ) or regulatory protein during central nervous system development ${ }^{5}$ (RPTP $\left.\beta\right)$. Although these proteins are cloned and their putative localization is identified, further studies are needed to determine their exact role.

Over the past decades, serious efforts have been made to find the role of CA in tumor progression, either as a biomarker or a tumor-associated protein. The expression of CA I and CA II has been most frequently investigated in a variety of tumor cells and cell lines, ${ }^{10}$ but it has been difficult to find a clear-cut relationship between the expression of CA isozymes in normal and malignant cells. On the basis of the very few preliminary studies performed, it can be concluded that CA isozymes I through VII, which are expressed in normal tissues with differing intensity, may also be expressed in the malignant cell lines derived from the CA-expressing cells. However, no evidence of a direct relationship between malignant transformation and CA expression has been presented for CAs I through VII. It appears that only the recently characterized isoform CA IX is an exception, as its expression can be associated with tumorigenesis.

\section{CAs in Nervous System Tumors}

Expression of CA II was not informative in a variety of nervous system tumors, ${ }^{11,12}$ because CA II appeared in inappropriate cell types not corresponding to the original restricted localization of CA II in the peripheral and central nervous system. Therefore, CA II did not prove restrictive enough to be useful for screening of nervous system tumors.

\section{CAs in Pancreatic and Colorectal Tumors}

Intense immunohistochemical staining for CA II was detected in normal and neoplastic ductal cell types of pancreatic exocrine tissue, whereas CA I was expressed in normal and malignant glucagon-producing pancreatic endocrine tissue. ${ }^{13}$ Normal colonic epithelium expresses

\footnotetext{
Accepted for publication March 24, 1998.

Address reprint requests to Antal Nógrádi, Department of Ophthalmology, Albert Szent-Gyorgyi Medical University, PO Box 407, 6701 Szeged, Hungary
} 
both CA I and CA II, but their expression is significantly reduced in colorectal tumors. ${ }^{14}$ It appears that there is a negative correlation between the expression of CA I/CA II in colorectal malignant mucosa and the cell proliferation index. ${ }^{15}$ In contrast to the reduced CA I/CA II immunoreactivity observed in colorectal tumors, these isozymes were more abundant in stool samples of patients suffering from colorectal cancer than in those of healthy individuals. This finding is difficult to interpret, because increased epithelial shedding and bleeding from the malignant colorectal tissue may obscure the exact nature of increased fecal CA I/II levels. ${ }^{16}$

\section{CA IX, the Tumor-Associated Isozyme}

CA IX was first found and characterized as a tumorassociated gene product in HeLa cells that had been co-cultured with breast carcinoma cells and was initially called MN protein. ${ }^{17}$ At this time, it was not yet clear that MN protein had the CA domain and activity. Later, it became evident that one important feature of the complex protein is its CA nature ${ }^{18}$; therefore, it is now called CA IX. CA IX is a transmembrane protein embedded in the cell membrane, although it can be immunohistochemically detected both on the cell surface and in the nucleus. ${ }^{19,20}$ Its molecular weight is $54 / 58 \mathrm{kd}$; the doubleband formation is probably due to posttranslational protein processing of a single gene product. ${ }^{18}$ Complementary DNA and genomic sequence analysis showed that the CA IX protein consists of an N-terminal proteoglycanlike region, a central CA domain, a cell surface anchor, and an intracytoplasmic tail. ${ }^{18,21}$ The $\mathrm{N}$-terminal region shows features of a helix-loop-helix protein and may possess a DNA-binding segment. This could explain the remarkable DNA binding capacity of CA IX. The middle and $\mathrm{C}$-terminal parts of the CA domain are highly conserved, and the protein exerts a weak CA activity and shows strong binding to zinc cations, which is typical of catalytically active CAs. ${ }^{18}$ The CA domain and the $\mathrm{N}$ terminal helix-loop-helix part are thought to act together in DNA binding, because in vitro binding of the protein with DNA occurs only in the presence of zinc cations. These features suggest a potential role for CA IX in regulation of cell proliferation and oncogenesis. Expression of CA IX in HeLa cells appears to be cell density-dependent. The protein is virtually not expressed by sparse cell groups, but abundant expression is induced in dense cultures. ${ }^{19}$ Moreover, in HeLa $\times$ fibroblast hybrid cells, CA IX expression correlates with the tumorigenicity of different hybrid cell lines. CA IX is absent in nontumorigenic hybrid cells but is expressed in tumorigenic clones. ${ }^{20,22}$ To study the role of the protein in regulation of cell growth and proliferation, NIH3T3 fibroblasts, which normally do not express CA IX, were transfected with a plasmid containing the CA IX gene. ${ }^{18}$ Transfected cells changed their morphology and became unable to arrest cell proliferation, suggesting a direct role for CA IX in cell growth regulation, when the protein is synthesized. These findings raised further questions about the nature of CA IX in normal and tumor cells. As CA IX was primarily found in carcinoma cell lines and malignant tissues but not in corresponding normal tissues, it was not clear whether the same intact $C A I X$ gene is expressed in normal and carcinogenic cells. Limited search for the localization of CA IX showed the presence of CA IX in some normal tissues of the human (and other mammalian) alimentary tract, such as stomach, intestinal, and gall bladder epithelia. Complementary DNA sequence analysis showed that the normal gastric CA IX CDNA sequence was identical with that of HeLa cells, excluding the possibility of the presence of a mutant $C A I X$ gene in the investigated tumor cells. ${ }^{23}$ However, in gastric tumor samples, CA IX expression is reduced or lost, suggesting a putative negative control of cell growth by CA IX in normal cells.

The protein was first exclusively found in human carcinoma cell lines and benign neoplasms of the genital system, but not in corresponding normal tissues. ${ }^{20}$ Liao et al have investigated the potential role of CA IX as a biomarker of cervical neoplasms. ${ }^{24}$ Because HeLa is a cell line derived from a cervical carcinoma and CA IX was first found in tumor cell lines derived from ovary, endometrium, and uterine cervix, Liao et al studied the diagnostic value of the MN protein in various cervical carcinomas, including cervical intraepithelial neoplasias. Normal cervical epithelium does not express the MN antigen apart from the occasional weak staining of very few basal and reserve cells. Expression of CA IX was immunohistochemically detected in both low- and highgrade dysplasias, in situ and invasive adenocarcinomas, and cervical carcinomas. It was a striking finding that normal cervical tissues adjacent to intraepithelial neoplasia exhibited moderate to strong staining in many reserve and some columnar cells. It can be concluded that normal reserve cells stain positively for MN when they enter a proliferative state, in particular in the presence of adjacent intraepithelial neoplasia or carcinoma. Thus, increased levels of immunohistochemically detectable MN antigen in cervical epithelium may require a strict clinical approach. It was also expected that exfoliative cells in cervical Papanicolaou smears would reflect the CA IX immunoreactivity alterations seen in whole tissue sections, and the level of gene expression in exfoliative cells would provide information about the presence of dysplasia in the cervix. ${ }^{25}$ This would be of particular interest, because Papanicolaou smears often give false negative results. ${ }^{26}$ Indeed, virtually all of the atypical and dysplastic columnar cells in the cytological smears derived from glandular dysplasia and in situ or invasive adenocarcinoma expressed significant levels of CA IX immunoreactivity. The reliability of CA IX immunoreactivity as a biomarker of dysplasia was tested by histological investigation of corresponding biopsy material, and CA IX expression in exfoliative cells recapitulated that in tissue sections. Moreover, it became evident that expression of CA IX in a small proportion of normal exfoliative cells is indicative of reserve cell hyperplasia, whereas CA IX expression in the majority of normal endocervical cells indicates the presence of squamous dysplasia. Lowgrade dysplastic cells expressing high levels of CA IX tend to progress to higher-grade dysplasia; thus, the 
presence of high CA IX immunoreactivity is indeed an early biomarker of glandular dysplasia and in situ or invasive adenocarcinoma. The most valuable and striking finding in this field is that expression of CA IX is a definite warning sign in those cells that have the cytological appearance of normal endocervical components even if no other marker indicates the presence of dysplasia. Thus, the use of CA IX expression may help in rescreening doubtful cervical Papanicolaou smears or biopsy materials, and thus, one may predict the progressive nature of dysplasia in very early stages of the hyperplasia.

Recent preliminary searches for distinct genetic sequences of the CA IX protein amplified with the reverse transcription-polymerase chain reaction technique have focused on the benign and malignant tissues of the human urogenital tract. CA IX mRNA was not detected in normal renal parenchyma, but strong mRNA signal was found in histologically identified clear-cell renal adenocarcinoma, the most common form of renal cancer. ${ }^{27}$ However, no significant mRNA signal was found in samples from papillary and granular tumors of the kidney. Interestingly, CA IX mRNA signal was observed in three human renal tumor cell lines (SKRC-01, SKRC-08, and SKRC-09) that have previously been shown to express the renal carcinoma-specific cell surface marker G250, which shows strong homology to CA IX. ${ }^{28}$ Three other renal carcinoma lines expressed neither CA IX nor G250. Further histological studies may elucidate whether CA IX is indeed a specific marker for clear-cell renal adenocarcinoma and whether the expression of CA IX depends on the level of differentiation of tumor cells.

Saarnio et $\mathrm{al}^{29}$ have provided evidence in this issue of The American Journal of Pathology for the clear-cut association of CA IX expression with cell proliferation of colorectal tumors and dysplasias. They detected CA IX in colorectal carcinomas and mapped the expression of the nuclear Ki-67 antigen in serial parallel sections. The Ki-67 antigen appears to be a reliable marker of cell proliferation in the colon. ${ }^{30}$ They presented evidence that CA IX expression was primarily localized to areas of rapid cell proliferation as indicated by Ki-67 immunoreactivity. CA IX was present in normal cryptal cells and in the cryptal area of hyperplastic polyps. Similar to findings in cervical dysplasias and carcinomas, CA IX showed intense immunoreactivity in surface epithelial cells of adenomas and a more diffuse staining pattern in carcinomas than in benign neoplasms.

It can be concluded that these preliminary studies have already shown the importance and usefulness of CA IX in histopathological diagnosis. However, it is not clear yet whether CA IX is really a good indicator of tumor differentiation. It appears that malignant tissues show a more diffuse staining pattern than benign tumors, but this feature of CA IX expression is too general to be applied to every tumor expressing CA IX. This protein is definitely associated with cell growth, but its role is not determined yet, although it cannot be excluded that CA IX is not only a biomarker but has an active role in cell cycle regulation. It is likely that CA IX is expressed by rapidly proliferating tumor cells or cells that are about to enter the proliferative state, because the CA domain and other elements of the molecule take part in the regulation of cell growth in certain tumor cell types. However, further studies should elucidate whether CA IX may be involved in the pathogenesis of certain tumors.

\section{References}

1. Meldrum NU, Roughton FJW: Carbonic anhydrase: its preparation and properties. J Physiol 1933, 80:113-141

2. Maren TH: Carbonic anhydrase: chemistry, physiology and inhibition. Physiol Rev 1967, 47:595-743

3. Tashian RE: The carbonic anhydrases: widening perspectives on their evolution, expression and function. Bioassays 1989, 10:186-192

4. Hewett-Emmett D, Tashian RE: Functional diversity, conservation, and convergence in the evolution of the $\alpha-, \beta$-, and $\gamma$-carbonic anhydrase gene family. Mol Phylogenet Evol 1996, 5:50-77

5. Levy JB, Canoll PD, Silvennoinen O, Barnea G, Morse B, Honegger AM, Huang J-T, Cannizzaro LA, Park S-H, Druck T, Huebner K, Sap J, Ehrlich M, Musacchio JM, Schlessinger J: The cloning of a receptortype protein tyrosine phosphatase expressed in the central nervous system. J Biol Chem 1993, 268:10573-10581

6. Kato K: Sequence of a novel carbonic anhydrase-related polypeptide and its exclusive presence in Purkinje cells. FEBS Lett 1990, 271: 137-140

7. Sly WS, Hu PY: Human carbonic anhydrases and carbonic anhydrase deficiencies. Annu Rev Biochem 1995, 64:375-401

8. Nógrádi A, Jonsson N, Walker R, Caddy K, Carter N, Kelly C: Carbonic anhydrase II and carbonic anhydrase-related protein in the cerebellar cortex of normal and lurcher mice. Dev Brain Res 1997, 98:91-101

9. Barnea G, Silvennoinen O, Shaanan B, Honegger AM, Canoll PD, D'Eustachio P, Morse B, Levy JB, Laforgia S, Huebner K, Musacchio JM, Sap J, Schlessinger J: Identification of a carbonic anhydrase-like domain in the extracellular region of RPTP $\gamma$ defines a new subfamily of receptor tyrosine phosphatase. Mol Cell Biol 1993, 13:1497-1506

10. Venta PJ: Carbonic anhydrases in mammalian cell culture and tumors. The Carbonic Anhydrases. Edited by SJ Dodgson, RE Tashian, G Gros, and ND Carter. New York, Plenum Press, 1991, pp 71-78

11. Kumpulainen T, Nyström SHM: Immunohistochemical localization of carbonic anhydrase isoenzyme C in human brain. Brain Res 1981, 220:220-225

12. Nakagawa $Y$, Perentes E, Rubinstein LJ: Non-specificity of anti-carbonic anhydrase $\mathrm{C}$ antibody as a marker in human neurooncology. J Neuropathol Exp Neurol 1987, 46:451-460

13. Parkkila S, Parkkila A-K, Juvonen T, Lehto V-P, Rajaniemi H: Immunohistochemical demonstration of the carbonic anhydrase isoenzymes I and II in pancreatic tumours. Histochem J 1995, 27:133-138

14. Gramlich TL, Hennigar RA, Spicer SS, Schulte BA: Immunohistochemical localization of sodium-potassium-stimulated adenosine triphosphatase and carbonic anhydrase in human colon and colonic neoplasms. Arch Pathol Lab Med 1990, 114:415-419

15. Mori M, Staniunas RJ, Barnard GF, Jessup JM, Steele GD, Chen LB: The significance of carbonic anhydrase expression in human colorectal cancer. Gastroenterology 1993, 105:820-826

16. Yokoyama S, Shatney CH, Mochizuki H, Hase K, Johnson DL, Cummings S, Trollope ML, Tamakuma S: The potential role of fecal carbonic anhydrase II in screening for colorectal cancer. Am Surg 1997, 63:243-247

17. Závada J, Závadová Z, Malî́ A, Kočent A: VSV pseudotype produced in a cell line derived from human mammary carcinoma. Nature New Biol 1972, 240:124-125

18. Pastorek J, Pastoreková S, Callebaut I, Mornon JP, Zelnik V, Opavsky̌ R, Zat'ovičová M, Liao S, Portetelle D, Stanbridge EJ, Závada J, Burny A, Kettmann R: Cloning and characterization of MN, a human tumorassociated protein with a domain homologous to carbonic anhydrase and a putative helix-loop-helix DNA binding segment. Oncogene 1994, 9:2877-2888

19. Pastoreková S, Závadová Z, Kostál M, Babusiková O, Závada J: A novel quasi-viral agent, MaTu, is a two-component system. Virology 1992, 187:620-626 
20. Závada J, Závadová Z, Pastoreková S, Čiampor F, Pastorek J, Zelnik V: Expression of MaTu-MN protein in human tumor cultures and in clinical specimens. Int J Cancer 1993, 54:268-274

21. Opavsky̌ R, Pastoreková S, Zelnik V, Gibadulinová A, Stanbridge EJ, Závada J, Kettmann R, Pastorek J: MN/CA9 gene, a novel member of the carbonic anhydrase family: structure and exon to protein domain relationships. Genomics 1996, 33:480-487

22. Stanbridge EJ, Der CJ, Doersen C-J, Nishimi RY, Peehl DM, Weissman BE, Wilkinson JE: Human cell hybrids: analysis of transformation and tumorigenicity. Science 1982, 215:252-259

23. Pastoreková S, Parkkila S, Parkkila A-K, Opavskŷ R, Zelnik V, Saarnio J, Pastorek J: Carbonic anhydrase IX, MN/CA IX: Analysis of stomach complementary DNA sequence and expression in human and rat alimentary tracts. Gastroenterology 1997, 112:398-408

24. Liao SY, Brewer C, Závada J, Pastorek J, Pastoreková S, Manetta A, Berman ML, DiSaia PJ, Stanbridge EJ: Identification of the MN antigen as a diagnostic biomarker of cervical intraepithal squamous and glandular neoplasia and cervical carcinomas. Am J Pathol 1994, 145:598-609

25. Liao SY, Stanbridge EJ: Expression of the MN antigen in cervical
Papanicolaou smears is an early diagnostic biomarker of cervical dysplasia. Cancer Epidemiol Biomarkers Prev 1996, 5:549-557

26. Koss LG: The Papanicolaou test for cervical cancer detection: a triumph and a tragedy. J Am Med Assoc 1989, 261:737-743

27. McKiernan JM, Butyan R, Bander NH, Stifelman MD, Katz AE, Chen M-W, Olsson CA, Sawczuk IS: Expression of the tumor-associated gene MN: a potential biomarker for human renal cell carcinoma. Cancer Res 1997, 57:2362-2365

28. Oosterwijk E, de Weijert M, von Bokhoven A, Brakenhof RH, Peelen WP, Debruyne FMJ: Molecular characterization of the renal cell carcinoma-associated antigen G250. J Urol 1996, 155:925

29. Saarnio J, Parkkila S, Parkkila A-K, Haukipuro K, Pastoreková S, Pastorek J, Kairaluoma MI, Karttunen TJ: Immunohistochemical study of colorectal tumors for expression of a novel transmembrane carbonic anhydrase, MN/CA IX, with potential value as a marker of cell proliferation. Am J Pathol 1998, 153:279-285

30. Holt PR, Moss SF, Kapetanakis AM, Petros A, Wang S: Is Ki-67 a better proliferative marker in the colon than proliferating cell nuclear antigen? Cancer Epidemiol Biomarkers Prev 1997, 6:131-135 